\title{
BMJ Open FitSkills: protocol for a stepped wedge cluster randomised trial of a community-based exercise programme to increase participation among young people with disability
}

Nora Shields (D) , ${ }^{1}$ Claire Willis (D) , ${ }^{1}$ Christine Imms (D) , ${ }^{2}$ Luke A Prendergast (i) , ${ }^{3}$ Jennifer J Watts (D) , ${ }^{4}$ Ben van Dorsselaer, ${ }^{1}$ Georgia McKenzie, ${ }^{1}$ Andrea M Bruder (D) , ${ }^{1}$ Nicholas F Taylor (D) , ${ }^{1,5}$ The FitSkills Partnership Project Group

To cite: Shields N, Willis C, Imms C, et al. FitSkills: protocol for a stepped wedge cluster randomised trial of a community-based exercise programme to increase participation among young people with disability. BMJ Open 2020;10:e037153. doi:10.1136/ bmjopen-2020-037153

- Prepublication history and additional material for this paper are available online. To view these files, please visit the journal online (http://dx.doi. org/10.1136/bmjopen-2020037153).

Received 22 January 2020 Revised 05 June 2020 Accepted 05 June 2020

Check for updates

(C) Author(s) (or their employer(s)) 2020. Re-use permitted under CC BY-NC. No commercial re-use. See rights and permissions. Published by BMJ.

For numbered affiliations see end of article.

Correspondence to

Prof Nora Shields;

n.shields@latrobe.edu.au

\section{ABSTRACT}

Introduction There is a need to develop relevant, acceptable initiatives that facilitate physical activity participation in young people with disability. FitSkills was developed to support young people with disability to exercise. The primary aims are to investigate if FitSkills can be scaled up from a small, university-led programme to run as a larger community-university partnership programme, and to determine its effectiveness in improving physical activity participation and healthrelated quality of life for young people with disability. The secondary aims are to evaluate cost-effectiveness, changes in attitudes towards disability and other healthrelated outcomes for young people with disability.

Methods and analysis A stepped wedge cluster randomised trial using a cohort design and embedded health economic evaluation will compare the effect of FitSkills with a control phase. FitSkills matches a young person with disability with a student mentor and the pair exercise together at their local gymnasium for 1 hour, two times per week for 12 weeks (24 sessions in total). One hundred and sixty young people with disability aged 13 to 30 years will be recruited. Eight community gymnasia will be recruited and randomised into four cluster units to have FitSkills introduced at 3-month intervals. Primary (feasibility, participation and health-related quality of life) and secondary outcomes will be collected longitudinally every 3 months from trial commencement, with eight data collection time points in total. The Practical Robust Implementation and Sustainability Model will be used to support knowledge translation and implementation of project findings into policy and practice.

Ethics and dissemination Ethical approval was obtained from the La Trobe University Human Ethics Committee (HEC17-012), Australian Catholic University (2017-63R), Deakin University (2017-206) and the Victorian Department of Education and Training (2018_003616). Results will be disseminated through published manuscripts, conference presentations, public seminars and practical resources for stakeholder groups. Trial registration number ACTRN12617000766314.

\section{Strengths and limitations of this study}

- To our knowledge, this will be the first implementation trial to evaluate the effectiveness and cost-effectiveness of a community-based, participation-focussed exercise programme for young people with disability.

- The intervention (called FitSkills) is designed to address two main barriers to physical activity participation identified in previous research by young people with disability, a lack of social support and a lack of appropriate inclusive, community-based programmes.

- The trial protocol was designed in partnership with consumers, community organisations and government stakeholders.

- FitSkills is designed as a gymnasium-based exercise programme and does not address alternative physical activity preferences of young people with disability.

Trial sponsor La Trobe University.

\section{INTRODUCTION}

Disability is an umbrella term for problems in body function or structure (impairments), difficulties in executing activities (activity limitations) or problems in involvement in life situations (participation restrictions). ${ }^{1}$ People with disability have lower levels of fitness than those without disability ${ }^{23}$ and are more likely to develop earlier onset of secondary health conditions related to their disability, such as osteoporosis, ${ }^{4}$ heart disease, ${ }^{5}$ diabetes ${ }^{6}$ and obesity. ${ }^{7}$ They have high rates of co-occurring impairments ${ }^{8}$ including pain, epilepsy, continence issues, sleep and behaviour disorders and sensory deficits, and are more likely to 
have poor psychological health $(15 \%$ vs $8 \%$ in young people) and depression (30\% vs $19 \%$ in adults) than the general community. ${ }^{5}$ Young people with disability have poorer health outcomes and are more socially isolated than their typically developing peers. ${ }^{4578}$ People with disability experience more disadvantage than their peers without disability, including lower rates of school completion and employment, higher reliance on government support ${ }^{9}$ and reduced social participation..$^{10}$ As a result, people with disability, including those with intellectual disability, ${ }^{11}{ }^{12}$ cerebral palsy ${ }^{13}$ and spina bifida, ${ }^{14}$ have lower life expectancy than the general population.

Increasing participation in exercise, a structured form of physical activity, among young people with disability is a public health priority as typically they do not participate in recommended levels of physical activity. WHO guidelines recommend that adolescents participate in at least $60 \mathrm{~min}$ of moderate-to-vigorous intensity physical activity each day and adults participate in at least $150 \mathrm{~min}$ of moderate intensity physical activity each week. ${ }^{15}$ Young people with cerebral palsy participate in $13 \%$ to $53 \%$ less physical activity than their typically developing peers, ${ }^{16}$ and their activity levels are $30 \%$ lower and sedentary times $50 \%$ higher than recommended. ${ }^{16}$ People with intellectual disability are also less active than the general public $(22 \%$ vs $60 \%) .{ }^{5}$ Lack of physical activity is the fourth leading risk factor for global mortality, accounting for $6 \%$ to $9 \%$ of all deaths in the general population. ${ }^{17}$ People who exercise as little as $15 \mathrm{~min}$ per day have a $14 \%$ reduced risk of all-cause mortality and a 3-year longer life expectancy than those who are inactive. ${ }^{18}$ The economic benefits of increasing exercise participation are large; increasing physical activity levels by $10 \%$ in Australia would result in 2000 fewer deaths per year and 25000 fewer disability adjusted life years, reducing health sector costs by 96 million Australian dollars. ${ }^{19}$ For these reasons, the promotion of exercise is a significant public health initiative across the lifespan for all, including those with disability.

The physical and social health issues of young people with disability could be ameliorated by increasing their participation in community-based exercise. Evidence shows participation in exercise improves fitness, ${ }^{20-22}$ increases social interactions ${ }^{23}$ and improves socialemotional functioning ${ }^{24}$ in young people with disability. Further, qualitative research reporting the lived experience of young people with disability indicates their participation in exercise increases inclusion, friendship, independence, choice, confidence and is the impetus for healthier lifestyles. ${ }^{25}{ }^{26}$ It also helps negate any negative perceptions of having a disability. ${ }^{25}$ However, young people with disability face complex and multifactorial barriers to participation in exercise ${ }^{27}$ including environmental, social, attitudinal and personal factors. For example, many community exercise programmes that aim to increase participation among young people with disability are segregated, despite the fact that young people with disability seek inclusive exercise options. ${ }^{28}$
Two key barriers to participation in exercise for young people with disability are the need for assistance to exercise (social support) and a lack of suitable inclusive programmes. ${ }^{29}$

We developed and demonstrated the efficacy of a programme that overcomes these key barriers for young people with disability, facilitating their participation in exercise. The key features of the programme are: (1) the inclusion of a mentor providing social support and (2) it is based in the community where the young person lives. There is evidence the programme is effective in the short-to-medium term in improving fitness and maintaining exercise participation among young people with disability. ${ }^{30-32}$ Benefits also extend to mentors who develop an understanding and more positive attitudes towards disability in addition to professional skills. ${ }^{33-35}$ Based on this, in 2014 we established FitSkills, a small fee-for-service university-run programme in Melbourne, Australia, for approximately 25 participants per annum. We evaluated FitSkills through a prospective feasibility study of 19 young people (nine female; mean age $18.4 \pm 4.5$ years) with disability. ${ }^{36}$ The feasibility study showed FitSkills was well attended (91\% of scheduled sessions), had good adherence (resistance and aerobic training load was progressed), was safe (no serious adverse events) and led to sustained improvements in muscle strength and walking capacity. ${ }^{36}$ Importantly, data on participation in physical activities after the programme were available for 16 participants, 10 of whom had continued to exercise at the gymnasium, had taken up a new activity or both. ${ }^{36}$

Maintaining FitSkills as a university-led programme limits its size, scope and potential as a catalyst for practice and policy change. To achieve our goal of getting more young people with disability, more active, more often, the next step is to test if it can be implemented on a larger scale. The overarching aim of this trial therefore is to investigate if FitSkills can be scaled up from a smallscale university-led programme to a larger communityuniversity partnership that supports increased exercise participation among young people with disability. Our specific research questions are:

1. Can FitSkills be scaled up to run as a communityuniversity partnership?

2. Is FitSkills effective in improving exercise participation, health-related quality of life, physical activity, attitudes to exercise and walking capacity among young people with disability when implemented in a community setting?

3. Does FitSkills foster positive attitudes towards disability among mentors, gymnasium staff and gymnasium patrons?

4. Is FitSkills cost-effective compared with no intervention from a societal perspective, based on cost and healthrelated quality of life outcomes?

5. Can FitSkills be implemented as sustainable community practice? 


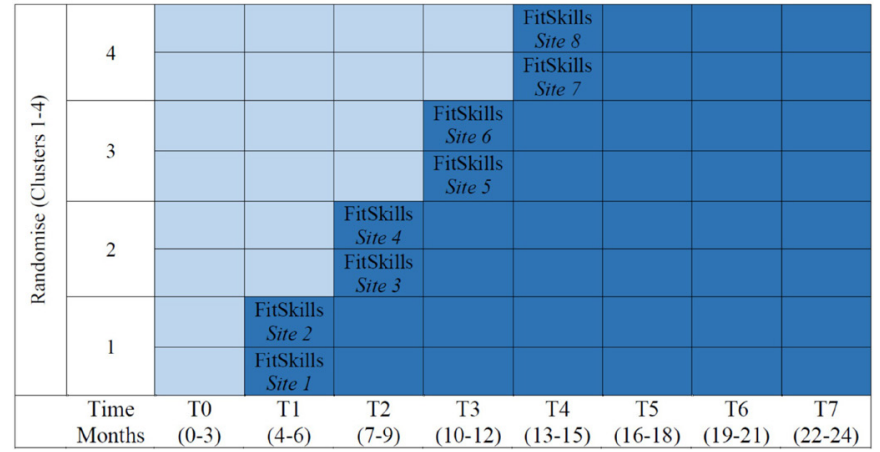

Figure 1 Schematic of stepped wedge design with four clusters, each with two sites (eight sites in total). Each 'step' is 3 months in duration. There are eight assessment points (T0 to T7) and assessments occur at the start of each new step. Light shading represents the control period. Dark shading represents the intervention period. Each step labelled FitSkills is when a site crosses to the intervention period.

\section{METHODS AND ANALYSIS \\ Trial design}

To address the aims of the trial we will complete a stepped wedge cluster randomised trial, within an effectivenessimplementation hybrid framework. ${ }^{37}$ The trial will use a cohort design and embedded health economic evaluation, to compare the effect of FitSkills with a control phase. This design sequentially introduces FitSkills to gymnasia (sites) in random order (figure 1). After an initial period when no sites are exposed (control phase), at regular intervals sites are randomised to cross from control to intervention phase $^{38}$ until all sites have implemented FitSkills. Data collection (at eight time points) will continue throughout the trial so participants contribute repeated observations under control and intervention phases. We will recruit eight sites (community gymnasia) in Melbourne, Australia. Each site represents a cluster unit. The trial design will comprise four groups each containing two randomly allocated cluster units. A member of the research team (LP) not involved in recruitment, assessment or intervention delivery will randomise the order of the eight sites using a web-based software. The trial has been registered (online supplementary appendix 1) with the Australian New Zealand Clinical Trials Registry.

\section{Participants}

One hundred and sixty young people with disability ( $n=20$ at each of the eight trial sites) will be recruited. Participants will be included if they are:

1. aged 13 to 30 years and identify as having a disability (any type including physical, intellectual and sensory).

2. able to follow simple verbal instructions in English (as determined by the Index of Social Competence). ${ }^{39}$

3. able to take part in a moderate-to-high intensity exercise programme. Participants will be screened using stage 1 of the Adult Pre-Exercise Screening System, ${ }^{40}$ and if indicated, medical clearance certifying they can participate in an exercise programme will be obtained. Participants will be excluded if they have:
1. participated in a high-intensity exercise programme within 3 months prior to the trial (to ensure any effects can be attributed to FitSkills).

2. an acute or concurrent medical condition rendering them unfit to take part (eg, severe cardiac conditions, uncontrolled epilepsy).

3. a significant psychological or behavioural problem that would impact their participation (eg, resistive behaviour, severe depression or severe anxiety).

Eligibility to participate in the trial will not be contingent on a young person's ability to complete particular outcome measures. As many of the outcome measures are questionnaires (see below), proxy report will be permitted.

\section{Recruitment}

Recruitment of participants will be by advertising through our partner organisations (Down Syndrome Victoria, Cerebral Palsy Support Network, Disability Sport and Recreation, City of Boroondara), our professional networks (including health professional groups), special and specialist developmental schools close to the trial sites, the Victorian Cerebral Palsy Register and through other community organisations that support or advocate for people with disability. Metropolitan councils in which the gymnasium sites are situated will also be approached to recruit participants living in these areas. A promotional flyer that briefly explains the purpose of the trial will be distributed by mail, email, social media, organisational newsletters and posted in public places such as libraries and community centres. The advertising material will ask young people with disability who are interested in participating and/or their family member, to contact the research team or the organisation from which they received the communication to obtain further information. All participants will complete a comprehensive screening process with a member of the research team to determine their eligibility to take part.

\section{Intervention}

FitSkills matches a young person with disability with a mentor from their community and the pair exercise together at their local gymnasium. The mentor is not a personal trainer but exercises alongside the young person with disability. This is to imbue as much as possible a peer relationship between the pair. FitSkills runs for 12 weeks with two 1-hour sessions per week (24 in total).

The exercise content comprises progressive resistance and/or aerobic training, individually tailored to the young person with disability and prescribed by exercise professionals from the research team according to best practice guidelines. ${ }^{41}$ To facilitate individual tailoring of the exercise prescription, participants will complete a consultation with a member of the research team at the gymnasium site they are allocated to immediately prior to receiving the intervention. Exercise prescription will be guided by participants' goals and preferences, ${ }^{42}{ }^{43}$ as young people with disability value the opportunity for 
choice in meaningful activity. An environment-focussed approach $^{4445}$ will include adaptions for some participants, such as exercising during quieter times at the gym, reducing the need for transfers and optimising the physical environment (eg, make use of large, clear spaces) for those who use mobility devices. We will foster self-efficacy by exposing participants to novel exercises and equipment, by providing opportunity to try and succeed at new tasks and by promoting collaborative, solutions-focussed problem solving. ${ }^{46} 47$

To assist the participants to plan ongoing participation in exercise after FitSkills, they will be provided with a booklet with information about benefits of continuing to exercise and how they can participate in exercise. The booklet will include a link to a state government funded information website that aims to assist people with disability identify and connect with physical activity opportunities in their locality (https://aaavic.org.au). All participants can continue to receive their usual healthcare during the trial, including attending their general practitioner, physiotherapist or other specialists.

\section{Mentors}

Mentors will be recruited from allied health student cohorts (any discipline and year level) from La Trobe University and health science student cohorts (physiotherapy, occupational therapy, exercise physiology, exercise science, speech pathology, podiatry, dietetics) from the Australian Catholic University in Melbourne. All mentors will need to hold current police and working with children checks. Mentors are volunteers who are selected based on residential location and are matched with a young person with disability from the same locality. All mentors will complete a 3-hour training session including programme content, motivational and support strategies for the young people with disability and a practical orientation to the gymnasium setting and equipment. As mentors may not have pre-existing knowledge of exercise training or disability, they will maintain fortnightly contact with the research team to reflect on their experiences and address any issues that arise. To monitor intervention fidelity, mentors and participants will maintain an exercise log, including a record of the exercises completed (eg, type and dose), adverse events and missed sessions.

\section{Outcome measures}

Outcomes will be assessed eight times at 3-month intervals (figure 1). Assessors will be blinded and will have no involvement in recruitment, randomisation or delivery of FitSkills. Assessors, who are registered allied health professionals, will complete a-2 hour training session outlining the trial outcome measures and data collection methods. Assessments will be completed at trial sites where possible, at a location close to the trial site, or at participant's homes where necessary and appropriate. We will collect data on individual participant demographics (age, sex, disability type and severity, residence, vocational status) and health (secondary conditions).

\section{Feasibility}

Feasibility (research question 1) will be measured:

1. using data from our partner organisations to map numbers of their constituents living close to FitSkills sites and comparing to the number of enrolments;

2. comparing numbers of enquiries with enrolments in FitSkills;

3. documenting mentor expressions of interest;

4. using data from exercise logs documenting attendance during FitSkills, intervention fidelity (including exercise intensity) and adverse events (eg, delayed-onset muscle soreness, injuries requiring medical attention);

5. gaining perspectives of young people with disability, their families and mentors and gymnasium management and staff on FitSkills from semi-structured interviews; and

6. reviewing each gymnasium site's disability policy and procedures using National Information Communication Awareness Network guidelines. ${ }^{48}$

These data will contribute evidence of process effectiveness and factors influencing implementation relative to the framework proposed by Bowen et al. ${ }^{49}$

\section{Effectiveness}

The effect of the intervention (research question 2) will be assessed for the following outcomes: participation (attendance, involvement and experience), healthrelated quality of life, physical activity, attitudes to exercise and walking capacity. An overview of outcome variables, measures selected and their characteristics is presented in table 1. Participants will self-report where possible. Our assessors will be experienced in interacting with young people with disability including those with intellectual disability and they will use strategies such as providing clear appropriate instructions and allowing time for familiarisation during the assessments to facilitate participants to self-report. If a participant is unable to self-report (eg, health utilisation questionnaire) then those data will be collected by proxy-report usually from a parent or another close family member.

\section{Attitudes to disability}

Attitudes to disability (research question 3) will be measured for mentors using interviews the 5-item Discomfort scale ${ }^{50}$ which indicates respondent's level of discomfort when interacting with people with disability. Each of the five items is scored using a 6-point Likert type scale ( $1=\mathrm{I}$ disagree very much; $6=\mathrm{I}$ agree very much). This subscale exhibits sound measurement properties. ${ }^{50}$

\section{Health economic data}

An economic analysis will be included from a societal perspective as cost per quality adjusted life year saved (research question 4). A resource use questionnaire will be designed for this trial specifically and completed by participants and their families at each time point. Data 
Table 1 Characteristics of included measures of effectiveness

\begin{tabular}{|c|c|c|c|c|c|}
\hline Variable & Measure & Domains & What is scored & Rated/assessed by & Psychometrics \\
\hline \multirow[t]{3}{*}{$\begin{array}{l}\text { Participation } \\
\text { attendance } \\
\text { (being there) }\end{array}$} & $\begin{array}{l}\text { Adolescent Physical } \\
\text { Activity Recall } \\
\text { Questionnaire }\end{array}$ & $\begin{array}{l}\text { Formal (organised) } \\
\text { Informal (non-organised) } \\
\text { physical activities }\end{array}$ & $\begin{array}{l}\text { Number of activities; } \\
\text { frequency attended; } \\
\text { time spent in activity }\end{array}$ & $\begin{array}{l}\text { Self-rated; recall of } \\
\text { typical week in the } \\
\text { past } 3 \text { months }\end{array}$ & $\begin{array}{l}\text { Acceptable to good retest reliability } \\
\text { (\% agreement }>70 \% \text {; weighted kappa } \\
>0.5 ; \text { ICC }=0.3 \text { to } 0.9 \text { ) across age, sex } \\
\text { and seasons. Evidence of construct } \\
\text { validity (associated with aerobic } \\
\text { fitness) }{ }^{59} \text { in Australian adolescents. }\end{array}$ \\
\hline & $\begin{array}{l}\text { Adolescent } \\
\text { Sedentary Activity }\end{array}$ & $\begin{array}{l}\text { Sedentary behaviours ( } 11 \\
\text { items) }\end{array}$ & Time spent sedentary & $\begin{array}{l}\text { Self-rated; recall of } \\
\text { normal week }\end{array}$ & $\begin{array}{l}\text { Good to excellent reliability (ICC }=0.57 \\
\text { to } 0.86 \text { ); good face validity }{ }^{60} \text { in } \\
\text { Australian adolescents. }\end{array}$ \\
\hline & $\begin{array}{l}\text { Children's } \\
\text { Assessment of } \\
\text { Participation and } \\
\text { Enjoyment (activities } \\
\text { outside school) }^{61}\end{array}$ & $\begin{array}{l}16 \text { items }{ }^{62} \text { : martial } \\
\text { arts; swimming; water } \\
\text { sports; horseback riding; } \\
\text { athletics; gymnastics; } \\
\text { dancing; learning to } \\
\text { dance; bicycling; walking; } \\
\text { snow sports; playing } \\
\text { on equipment; playing } \\
\text { games; individual physical } \\
\text { activities; non-team sports; } \\
\text { team sports }\end{array}$ & $\begin{array}{l}\text { Diversity (number of } \\
\text { activities); Frequency } \\
\text { per week (<oncea } \\
\text { month; once a month; } \\
\text { two to three times a } \\
\text { month; once a week; } \\
\text { two to three times a } \\
\text { week; once a day or } \\
\text { more) }\end{array}$ & $\begin{array}{l}\text { Self-rated; recall of } \\
\text { past } 3 \text { months }\end{array}$ & $\begin{array}{l}\text { Validity and reliability of using } 16 \\
\text { items and a 3-month recall period is } \\
\text { unknown }\end{array}$ \\
\hline $\begin{array}{l}\text { Participation } \\
\text { involvement } \\
\text { (experience of } \\
\text { participation) }\end{array}$ & $\begin{array}{l}\text { Participation } \\
\text { and Environment } \\
\text { Measure for Children } \\
\text { and Youth } \\
\text { 63 }\end{array}$ & Community (10 items) & $\begin{array}{l}\text { Frequency (8-point } \\
\text { scale: daily to never); } \\
\text { Involvement (5-point } \\
\text { scale: minimally } \\
\text { to very); Desire for } \\
\text { change (no change; } \\
\text { more often; less often; } \\
\text { more involved; less } \\
\text { involved; broader } \\
\text { variety of activities) }\end{array}$ & $\begin{array}{l}\text { Self-rated or proxy- } \\
\text { rated; recall of past } 3 \\
\text { months }\end{array}$ & $\begin{array}{l}\text { Good internal consistency for } \\
\text { community participation frequency } \\
(\mathrm{ICC}=0.70) \text { and involvement } \\
(\mathrm{ICC}=0.75) \text {. Good retest reliability for } \\
\text { community frequency }(\mathrm{ICC}=0.79)^{64} \\
\text { for } 5-17 \mathrm{y} / \mathrm{o} \text { with various disability } \\
\text { diagnoses. } \\
\text { Validity and reliability of using a } \\
3 \text {-month recall period is unknown. }\end{array}$ \\
\hline $\begin{array}{l}\text { Participation } \\
\text { experiences }\end{array}$ & $\begin{array}{l}\text { Self-reported } \\
\text { Experiences of } \\
\text { Activity Settings }^{65}\end{array}$ & $\begin{array}{l}22 \text { items, } 5 \text { domains: } \\
\text { personal growth; } \\
\text { psychological } \\
\text { engagement; social } \\
\text { belonging; meaningful } \\
\text { interactions; choice and } \\
\text { control }\end{array}$ & $\begin{array}{l}\text { 7-point scale with } \\
\text { labelled endpoints; } \\
\text { strongly disagree to } \\
\text { neither to strongly } \\
\text { agree }\end{array}$ & $\begin{array}{l}\text { Self-rated; } \\
\text { situation specific } \\
\text { activity setting (ie, } \\
\text { gymnasium) }\end{array}$ & $\begin{array}{l}\text { Good to excellent internal } \\
\text { consistency (Cronbach's } \alpha=0.71 \text { to } \\
0.88 \text { ) and moderate retest reliability } \\
\text { (mean ICC }=0.68)^{65} \text { in } 13-23 \text { y/o with } \\
\text { and without disability. }\end{array}$ \\
\hline \multirow[t]{2}{*}{ Environment } & $\begin{array}{l}\text { Measure of } \\
\text { Environmental } \\
\text { Qualities of Activity } \\
\text { Settings }^{6667}\end{array}$ & $\begin{array}{l}32 \text { qualities, } 61 \text { items, } \\
3 \text { domains: welcoming } \\
\text { atmosphere; aesthetic, } \\
\text { physical and social } \\
\text { qualities; opportunity } \\
\text { related qualities }\end{array}$ & $\begin{array}{l}7 \text {-point scale; } 1=\text { not at } \\
\text { all, } 7=\text { very great extent }\end{array}$ & $\begin{array}{l}\text { Observer reported } \\
\text { of a specified setting } \\
\text { (gymnasium) }\end{array}$ & $\begin{array}{l}\text { Evidence for factor structure and very } \\
\text { good to excellent internal consistency } \\
\text { (Cronbach's } \alpha=0.76 \text { to } 0.96 \text { ), good to } \\
\text { excellent inter-rater (ICC }=0.60 \text { to } 0.93 \text { ) } \\
\text { and good to excellent retest reliability } \\
\text { (ICC=0.70 to } 0.90)^{66}\end{array}$ \\
\hline & $\begin{array}{l}\text { Participation } \\
\text { and Environment } \\
\text { Measure for Children } \\
\text { and Youth } \\
\text { 54 }\end{array}$ & Environment (16 items) & $\begin{array}{l}\text { Things that help } \\
\text { / hinder (not an } \\
\text { issue, usually helps, } \\
\text { sometimes helps, } \\
\text { usually makes it } \\
\text { harder); Adequacy of } \\
\text { supports (not needed, } \\
\text { usually yes, sometimes } \\
\text { yes, usually no) }\end{array}$ & $\begin{array}{l}\text { Self-rated or proxy- } \\
\text { rated; recall of past } 3 \\
\text { months }\end{array}$ & $\begin{array}{l}\text { Evidence of internal consistency } \\
\text { (Cronbach's } \alpha=0.67 \text { to } \geq 0.80 \text { ) and } \\
\text { good retest reliability (ICC }=0.76 \\
\text { to } 0.96)^{64} \text { in } 5-17 y / 0 \text { with various } \\
\text { disability diagnoses. } \\
\text { Validity and reliability of using a } \\
\text { 3-month recall period is unknown. }\end{array}$ \\
\hline
\end{tabular}




\begin{tabular}{|c|c|c|c|c|c|}
\hline Variable & Measure & Domains & What is scored & Rated/assessed by & Psychometrics \\
\hline \multirow[t]{2}{*}{$\begin{array}{l}\text { Health-related } \\
\text { quality of life } \\
\text { and well-being }\end{array}$} & $\begin{array}{l}\text { Child Health Utility-9 } \\
\text { Dimensions }^{68}\end{array}$ & $\begin{array}{l}9 \text { items: worried; sad; pain; } \\
\text { tired; annoyed; schoolwork } \\
\text { or work; sleep; daily } \\
\text { routine; activities }\end{array}$ & $\begin{array}{l}\text { 5-point scale per } \\
\text { question }\end{array}$ & $\begin{array}{l}\text { Self-report about } \\
\text { what 'is most like } \\
\text { you today' }\end{array}$ & $\begin{array}{l}\text { Developed for children aged } 7-11 \\
\text { years; } 6970 \text { evidence of criterion validity } \\
\text { (Spearman's } \rho=0.61 \text { ) in Australian } \\
\text { adolescents }^{71}\end{array}$ \\
\hline & $\begin{array}{l}\text { Life Satisfaction } \\
\text { Scale }^{72}\end{array}$ & $\begin{array}{l}20 \text { items, } 6 \text { domains: free- } \\
\text { time, health and wellness, } \\
\text { school, work, living } \\
\text { arrangement, social }\end{array}$ & $\begin{array}{l}\text { 3-point Likert scale, } \\
\text { Score range: } 0-40 \\
\text { Higher scores=better } \\
\text { satisfaction }\end{array}$ & $\begin{array}{l}\text { Self-report } \\
\text { satisfaction }\end{array}$ & $\begin{array}{l}\text { Good retest reliability }(\mathrm{ICC}=0.60) \text { in } \\
\text { youth with intellectual disability }{ }^{22} 73\end{array}$ \\
\hline \multirow[t]{3}{*}{$\begin{array}{l}\text { Attitudes to } \\
\text { exercise }\end{array}$} & $\begin{array}{l}\text { Exercise Barriers } \\
\text { Scale }^{72}\end{array}$ & $\begin{array}{l}18 \text { items, } 2 \text { factors: } \\
\text { cognitive-emotional } \\
\text { barriers and access } \\
\text { barriers }\end{array}$ & $\begin{array}{l}\text { 5-point Likert scale } \\
\text { (1=strongly agree to } \\
5=\text { strongly disagree); } \\
\text { Higher score=more } \\
\text { barriers to participation }\end{array}$ & $\begin{array}{l}\text { Self-perceived } \\
\text { barriers for people } \\
\text { with disability }\end{array}$ & 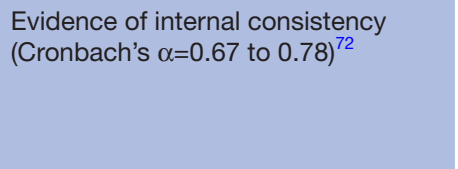 \\
\hline & $\begin{array}{l}\text { Exercise Outcomes } \\
\text { Scale }^{72}\end{array}$ & 9 items & $\begin{array}{l}\text { 3-point scale: agree, } \\
\text { neither, disagree. } \\
\text { Higher score=higher } \\
\text { perceived benefit }\end{array}$ & $\begin{array}{l}\text { Self-rated perceived } \\
\text { benefits of exercise }\end{array}$ & $\begin{array}{l}\text { Moderate-to-high retest reliability } \\
(\mathrm{ICC}=0.72) \text { in adults with intellectual } \\
\text { disability }^{72} 73\end{array}$ \\
\hline & $\begin{array}{l}\text { Self-Efficacy } \\
\text { Measure }^{72}\end{array}$ & 5 items & $\begin{array}{l}\text { 3-point scale: not at } \\
\text { all sure, a little sure, } \\
\text { totally sure. Higher } \\
\text { score=higher self- } \\
\text { efficacy }\end{array}$ & $\begin{array}{l}\text { Self-rated } \\
\text { confidence in } \\
\text { performing exercise }\end{array}$ & $\begin{array}{l}\text { Moderate retest reliability in adults } \\
\text { with intellectual disability }(\mathrm{ICC}=0.52)^{72} \\
73\end{array}$ \\
\hline $\begin{array}{l}\text { Physical } \\
\text { activity }\end{array}$ & $\begin{array}{l}\text { ActiGraph GT3X } \\
\text { activity monitor worn } \\
\text { on the waist }\end{array}$ & $\begin{array}{l}\text { Time spent in moderate- } \\
\text { to-vigorous intensity } \\
\text { activity based on } 8 \text { days of } \\
\text { wear during waking hours } \\
\text { (1 day familiarisation, } 7 \\
\text { days data collection) }\end{array}$ & $\begin{array}{l}\text { Data managed using } \\
\text { ActiLife software: } \\
\text { wear time (Choi } \\
\text { algorithm); intensity } \\
\text { using recommended } \\
\text { cut-points }\end{array}$ & $\begin{array}{l}\text { Adherent if worn } \\
\text { for at least } 10 \text { hours } \\
\text { on at least } 4 \text { days } \\
\text { including } 1 \text { weekend } \\
\text { day }\end{array}$ & $\begin{array}{l}\text { Excellent reliability (ICC=0.94 to } \\
0.99),{ }^{74} \text { good concurrent validity } \\
\text { (rho=0.70 to } 0.85),{ }^{74} \text { moderate } \\
\text { to perfect intensity classification } \\
\text { agreement ( } \kappa=0.51 \text { to } 0.85)^{75} \text { for } \\
\text { estimating physical activity and } \\
\text { sedentary behaviour in youth with } \\
\text { disabilities }^{7475}\end{array}$ \\
\hline $\begin{array}{l}\text { Walking } \\
\text { capacity }\end{array}$ & $\begin{array}{l}\text { Six-minute walk } \\
\text { test }^{76}\end{array}$ & $\begin{array}{l}\text { Modified technique that } \\
\text { allows encouragement, } \\
\text { and no practice walk }\end{array}$ & Distance in metres & $\begin{array}{l}\text { Total distance } \\
\text { walked in } 6 \text { min over } \\
\text { a } 20 \mathrm{~m} \text { track }\end{array}$ & $\begin{array}{l}\text { Reliable in young people with } \\
\text { disability (ICC=0.84 to } 0.97 \text { ). Evidence } \\
\text { of concurrent validity (associated with } \\
\text { physical activity levels) }\end{array}$ \\
\hline
\end{tabular}

ICC, intra-cluster correlation coefficient; y/o, year old.

will be collected on gym attendance (time, travel, out-ofpocket expenses), general health service use including health service use if injured during the intervention (hospital attendance, admission, consultations, investigations) and socioeconomic status (employment, income, carer requirement). Data will be collected from mentors to determine the cost of their participation (time, travel, out-of-pocket expenses). Health-related quality of life data will be assessed using the Child Health Utility-9D instrument (table 1). The health economic analysis will also inform organisational and policy decision-making about sustainability (research question 5).

\section{Data analysis}

\section{Sample size estimation}

At the time of proposal, a suitable sample size algorithm for stepped-wedge trials using cohort designs had not yet been established, other than for very simple settings. Therefore, we used simulation techniques to estimate sample size for a required power of $90 \%$. A total of 1000 data sets using a random effects model with normally distributed error terms and random effects to account for clustering, and six post-baseline time points replicating a two-at-a-time gymnasium allocation to treatment starting at the first time point after baseline were simulated using model parameter choices guided by the pilot data. ${ }^{36}$ This included a conservative treatment effect of a mean increase of $50 \mathrm{~m}$ hypothesised for the $6 \mathrm{~min}$ walk test (in the pilot data ${ }^{36}$ it was $80 \mathrm{~m}$ post treatment) and SD parameters for the error, individual random effect and gymnasium random effect of 90, 130 and 45, respectively.

To account for possible underestimation of variances in the pilot data ${ }^{36}$ which could artificially inflate power, the error and individual random effect SD were conservatively chosen, that is, increased, based on the pilot study estimates of approximately 80 and 95 respectively. The gymnasium random effect $\mathrm{SD}$ was chosen to provide a plausible intra-cluster correlation coefficient (ICC) of 0.2 to allow for some correlation between individuals within gymnasiums. These choices resulted in plausible simulated data based on differences between baseline and post-treatment. To simulate power, a linear mixed effects model was used to estimate the treatment effect based on baseline, post-treatment and 3-month follow-up similar to our pilot study. ${ }^{36}$ Simulations for eight gymnasia involving 20 young people with disability per gymnasium (total sample $n=160$ ) estimated power of $90 \%$ allowing for a 
dropout rate of up to $20 \%$. We did not include additional covariates to reduce the number of parameter values that needed to be proposed to conduct the sample size simulation.

We chose to perform our power and sample size simulation on the 6 min walk test as it is the only outcome testing efficacy that is common to our pilot trial ${ }^{36}$ and our proposed larger trial. However, our pilot data ${ }^{36}$ also included data on health-related quality of life measured using the KIDSCREEN-52 questionnaire, which assesses a similar construct to the Child Health Utility measure to be used in the proposed trial. Based on data for the dimension of physical well-being (measured in the KIDSCREEN-52), selected because it has the most immediate relevance to an exercise intervention, and choosing conservative SD for the error term and random effect of 4 and 4.5, respectively, (they were 3.4 and 4.2 in the pilot $\operatorname{trial}^{36}$ ) and a SD for gymnasia of 2, which allowed for an ICC of 0.2 , the proposed trial is powered for a conservative increase of $5 \%$ in health-related quality of life (simulated power $>86 \%$ ).

We based the sample size calculation on secondary (efficacy) outcomes on the assumption this sample will also be sufficient to address the primary feasibility aims of the trial. Our pilot trial ${ }^{36}$ conducted with 19 participants provided data sufficient to conclude the intervention was feasible on a small scale. As the current trial aims to investigate if FitSkills can be scaled up, a sample size eight times the pilot trial should be sufficient to address this aim. For example, we expect data saturation from semi-structured interviews for the feasibility domain of acceptability to be reached well within this sample size.

\section{Analysis of quantitative outcomes}

All quantitative analyses will be conducted according to intention-to-treat analysis principles, unless otherwise specified. Due to the nature of the intervention (exercise), it is not possible to blind participants, therefore, self-reported outcomes cannot be truly assessor-blinded. However, for outcomes where assessors collect the data (eg, walking capacity), the assessor will be unaware of when participants crossed from the control to the intervention phase. Given the pragmatic nature of the trial and the lack of guidance from the literature, we will combine self-report and proxy-report data for the same measures for analysis. Due to the assumptions made in combining these data, we will complete subgroup analyses on the self-report and proxy-report data separately (acknowledging the potential for these analyses to be underpowered).

Continuous data and costs will be analysed using linear mixed effects models with random effects to account for correlation within individuals and for clustering within sites. A random slope effect will also be used for the treatment effect to allow for heterogeneity across clusters. Linear mixed effects models are the recommended approach to analysing stepped wedge cluster data. ${ }^{51}$ Ordinal data will be analysed using Generalised Estimating Equations accounting for correlation within sites. Analyses will be adjusted for relevant baseline measures, such as age and sex, and seasonal effects will be considered. Sensitivity analysis for missing data will be carried out as per guidelines. ${ }^{52}$ Baseline characteristics associated with missingness will be included as covariates and the data modelled under the assumption of missing at random. Findings will be compared with results from other missing data strategies including multiple imputation and return-tobaseline. Bootstrapping will be used where costs show a skewed distribution.

\section{Analysis of qualitative outcomes}

The theoretical framework underpinning the qualitative data analysis is interpretive description. ${ }^{53}$ Interpretative description was chosen as its focus is on generating new knowledge by understanding complex experiential phenomena related to health rather than creating new theory. It seeks to generate understanding about the human experience in a way that can be meaningfully applied in clinical practice. The Consolidated criteria for Reporting Qualitative research (COREQ) checklist will be used to guide reporting. ${ }^{54}$

Audio-recorded participant interviews will be transcribed verbatim by a professional transcription service. Ideas that emerge in early interviews will be explored during later interviews to form a rich, nuanced understanding of the data. NVivo software (QSR International, Melbourne) will be used to manage the data analysis process. Analysis will commence with lineby-line coding of transcripts, by two researchers independently. After initial coding, the two researchers will meet to review the codes together. Inductive reasoning will be used to group the emergent codes into categories, subthemes and themes.

Strategies to ensure credibility, transferability and dependability of the data will be used including triangulation of data with other sources (eg, quantitative data, exercise logs) and using 'rich thick description', whereby direct verbatim quotations are included in reports. ${ }^{55}$ Coherent links between the data and reported findings will be established through member checking, providing an opportunity for participants to confirm that the transcripts reflect their thoughts and to verify the research team's interpretation of the data after the initial analysis.

\section{Health economic analysis}

The economic analysis will take a societal perspective. Mentor time will be costed at university rates and participant time will be costed using Australian average adult wage. Annual cost of capital (equipment, space) at the sites will be costed according to the opportunity cost method. Reasonable rental equivalent will be used to cost space. Health services will be costed according to the actual service used from various sources including Commonwealth Medicare Benefits Schedule (http:// 
www.mbsonline.gov.au), Independent Hospital Pricing Authority (https://www.ihpa.gov.au) and Transport Accident Commission for allied health services (http://www.tac.gov.au). Costs will be reported in 2019 Australian dollars. Incremental cost effectiveness ratios (ICERs) expressed as cost per quality adjusted life years saved will be calculated comparing costs and health-related quality of life outcomes between FitSkills and no intervention based on difference in costs and health-related quality of life utility index between the pre-intervention and post-intervention periods. The Consolidated Health Economic Evaluation Reporting Standards (CHEERS) will be used to guide reporting. ${ }^{56}$

\section{Patient and public involvement}

This proposal was co-developed by the research team and seven partner organisations: Victorian Department of Health and Human Services, City of Boroondara, Cerebral Palsy Support Network, Down Syndrome Victoria, Disability Sport and Recreation, YMCA Victoria and Joanne Tubb Foundation. The governance structure for the trial comprises a project steering committee, a disability advisory committee and a data monitoring committee. The project steering committee oversees and manages the budget, monitors implementation, provides strategic support and identifies and manages risks. This committee is led by an external chair, and membership includes the research team, one representative from each partner organisation and two consumer representatives. The steering committee meets monthly by videoconference and holds one annual face-to-face meeting.

The disability advisory committee advises on disability matters. It oversees the project from a disability perspective and identifies and advises on specific issues around project implementation. This committee is chaired by a member of the research team (CI) and includes at least three consumer representatives with disability recruited through our disability focussed partner organisations and one partner investigator. The data monitoring committee monitors safety and the integrity of data collection processes. This committee is chaired by a member of the research team (LP), a chief investigator, an independent expert clinician and at least one other member of the research team.

\section{ETHICS AND DISSEMINATION \\ Ethics}

Ethical approval was granted by university ethics committees before study commencement. Young adults with disability (aged 18 to 30 years) will usually provide their own written informed consent to participate in the trial. Where an adult with disability cannot provide their own consent (for example, they have a moderate level intellectual disability and usually do not provide their own consent) their parent or next of kin is asked to provide written informed consent on the adult's behalf.
In this case, the adult with disability is also invited to provide their written assent to participate. In the case of adolescents with disability (aged 13 to 17 years), written informed consent is obtained from their parents/ guardians. Adolescents with disability are also invited to provide their own written assent to participate based on their parents' recommendation for whether this is appropriate. Allocation is concealed at the time of consent.

\section{Safety}

Gymnasium staff will be the first responders to any medical emergencies at the gym sites. It is a requirement for all gym staff to hold First Aid qualifications. With permission, gymnasia will be provided with participant pre-exercise screening information including medical clearances to exercise.

\section{Dissemination}

We will use the Practical Robust Implementation and Sustainability $\mathrm{Model}^{57}$ to guide implementation, dissemination and knowledge translation of trial outcomes into ongoing practice (research question 5). This model provides a framework to understand external and internal factors influencing the implementation of FitSkills and to evaluate how the programme interacts with participants to influence adoption. It comprises four domains: programme, recipients, infrastructure and external environment. Within the programme domain, we will develop processes that meet our partners' needs (coordination across partners), maintain the essential elements of FitSkills during implementation (adaptability to local settings), monitor outcomes (observability), integrate a feedback mechanism (feedback of results), apply the National Information Communication Awareness Network Australia guidelines (organisational readiness) ${ }^{48}$ and design a clear and simple process (seamlessness of transition). Within the recipient domain, we will identify organisational champions (management support) and present FitSkills in the context of key partner organisational goals and values (cooperation). Within the infrastructure domain, we will identify key administrative and logistic tasks within existing organisational structures and plan possible devolvement of responsibilities (team), develop practical resources, such as materials and training, to assist implementation at new sites (training), gather exemplars and case studies (sharing best practice) and develop a business plan for FitSkills that could be adopted by other agencies (plan for sustainability). Within the external environment domain, we will develop referral pathways (community resources), invite participants to a celebration ceremony to recognise their achievements (payor satisfaction) and plan FitSkills to articulate with the Australian National Disability Insurance Scheme (reimbursement). In addition, we will disseminate outcomes broadly through published manuscripts, conference presentations, public seminars and a FitSkills website. 
In line with Australian National Health and Medical Research Council (NHMRC) polices, data from the trial will be available through Research Online, La Trobe University's Institutional Repository.

This trial aims to address the complex problem of how to engage young people with disability to participate in community-based exercise to improve their health and social outcomes. Article 30 of the United Nations Convention on the Rights of Persons with Disabilities, affirms the obligation to support the participation of young people with disability in recreational activities, leisure and sport. ${ }^{58}$ Currently, many young people with disability are unable to access opportunities for physical recreation, something their typically developing peers take for granted. FitSkills represents a social innovation to address this problem through partnerships with key stakeholders in the disability, recreation and government sectors by providing a viable solution to increase participation among young people with disability. Demonstrating if this approach is effective and costeffective when delivered on a larger scale may assist FitSkills being adopted by other agencies in the future.

\section{Author affiliations}

${ }^{1}$ Department of Physiotherapy, Podiatry and Prosthetics and Orthotics, La Trobe University, Melbourne, VIC, Australia

${ }^{2}$ Centre for Disability and Development Research, Australian Catholic University, Melbourne, VIC, Australia

${ }^{3}$ Department of Mathematics and Statistics, La Trobe University, Melbourne, VIC, Australia

${ }^{4}$ School of Health and Social Development, Faculty of Health, Deakin University, Burwood, Victoria, Australia

${ }^{5}$ Allied Health Clinical Research Office, Eastern Health, Melbourne, VIC, Australia

\section{Twitter Nora Shields @DrNoraShields}

Collaborators The FitSkills partnership project group comprises: Partner investigators: Jason Calleja, David Strickland, Shawn Stephenson (Sport and Recreation Victoria, Department of Jobs, Precincts and Regions, Department of Health and Human Services, Victoria); Michael P Walker (Health and Human Services Building Authority, Department of Health and Human Services, Victoria); Justine Robbins, Melissa Barkley, Cameron Geddes, Shane Lee (Joanne Tubb Foundation); Richard Amon, Juliet Ryan, Ayden Shaw (Disability Sport and Recreation); Simone Power, Rebecca McCabe, Shannon Cheal, Vicki Cavelieros (Cerebral Palsy Support Network); Debby Fraumano, Sue Blandford, Lucy Bain, Sonia Bonadio, Sue 0'Riley (Down Syndrome Victoria); Bernadette Roberts, John Summers, Troy Walker, Fiona Kriaris (YMCA Victoria); Sam Taylor, Tom Scanlan (City of Boroondara); Abigail Elliot (consumer representative); Lachlan O'Brien (consumer representative); Jenni Smith (independent chair, project steering committee). Project staff: Dr Stacey Cleary; Dr Brooke Adair; Dr Melissa Moore; Jess Kuek.

Contributors NS conceived FitSkills and led the research team in the conception, design and coordination of this trial, acquisition of funding and the drafting and critical revision of the manuscript. CW contributed substantially as the trial coordinator and the critical revision of the manuscript. $\mathrm{Cl}$ contributed to the trial design, acquisition of funding, is involved in the ongoing monitoring of trial progress, chairs the disability advisory committee and critically reviewed the manuscript. LP contributed to the trial design (sample size estimation and data analysis plan), acquisition of funding, is involved in the ongoing monitoring of trial progress and critically reviewed this manuscript. JJW contributed to the study design (economic evaluation component), acquisition of funding, project steering committees and critical revision of this manuscript. BvD contributed substantially as a research officer (participant and student mentor recruitment and training) and to the revision of the manuscript. GM contributed as a research student (qualitative data collection and analysis) and to the revision of the manuscript. AMB contributed as a research officer (exercise prescription, student mentoring) and to the revision of the manuscript. NFT contributed to the trial design, acquisition of funding, in ongoing monitoring of trial progress and critically reviewed the manuscript. All authors read and approved the final manuscript.

Funding This work was supported by Australian National Health and Medical Research Council (NHMRC) partnership project number 1132579. The trial also received financial (cash contributions) and substantial in-kind support from each of our partners: Victorian Department of Health and Human Services, City of Boroondara, Cerebral Palsy Support Network, Down Syndrome Victoria, Disability Sport and Recreation, YMCA Victoria and Joanne Tubb Foundation.

Competing interests None declared.

Patient and public involvement Patients and/or the public were involved in the design, or conduct, or reporting, or dissemination plans of this research. Refer to the Methods section for further details.

Patient consent for publication Not required.

Provenance and peer review Not commissioned; externally peer reviewed.

Open access This is an open access article distributed in accordance with the Creative Commons Attribution Non Commercial (CC BY-NC 4.0) license, which permits others to distribute, remix, adapt, build upon this work non-commercially, and license their derivative works on different terms, provided the original work is properly cited, appropriate credit is given, any changes made indicated, and the use is non-commercial. See: http://creativecommons.org/licenses/by-nc/4.0/.

\section{ORCID iDs}

Nora Shields http://orcid.org/0000-0002-6840-2378

Claire Willis http://orcid.org/0000-0002-3794-2902

Christine Imms http://orcid.org/0000-0001-9055-3554

Luke A Prendergast http://orcid.org/0000-0002-9122-5429

Jennifer J Watts http://orcid.org/0000-0001-8095-8638

Andrea M Bruder http://orcid.org/0000-0001-5422-5756

Nicholas F Taylor http://orcid.org/0000-0001-9474-2504

\section{REFERENCES}

1 World Health Organization. International classification of functioning disability and health (ICF. Geneva: WHO, 2001.

2 Rimmer JH. Physical fitness levels of persons with cerebral palsy. Dev Med Child Neurol 2001;43:208-12.

3 Baynard T, Pitetti KH, Guerra M, et al. Age-related changes in aerobic capacity in individuals with mental retardation: a 20-yr review. Med Sci Sports Exerc 2008:40:1984-9.

4 Cocks E, Thomson A, Thoresen S, et al. Health status and use of medications by adults with intellectual disability in Western Australia. J Intellect Dev Disabil 2016;41:87-96.

5 Department of Health. Victorian population health survey of people with an intellectual disability 2009. Melbourne: State Government of Victoria, 2011.

6 McVilly K, McGillivray J, Curtis A, et al. Diabetes in people with an intellectual disability: a systematic review of prevalence, incidence and impact. Diabet Med 2014;31:897-904.

7 Rimmer JH, Yamaki K, Lowry BMD, et al. Obesity and obesity-related secondary conditions in adolescents with intellectual/developmental disabilities. J Intellect Disabil Res 2010;54:787-94.

8 Novak I, Hines M, Goldsmith S, et al. Clinical prognostic messages from a systematic review on cerebral palsy. Pediatrics 2012;130:e1285-312.

9 Walsh J, Johnson S. Development and principles of the National disability insurance scheme. Aust Econ Rev 2013;46:327-37.

10 King M, Shields N, Imms C, et al. Participation of children with intellectual disability compared with typically developing children. Res Dev Disabil 2013;34:1854-62.

11 Bittles AH, Glasson EJ, Clinical GE. Clinical, social, and ethical implications of changing life expectancy in down syndrome. Dev Med Child Neurol 2004;46:282-6.

12 Heslop P, Glover G. Mortality of people with intellectual disabilities in England: a comparison of data from existing sources. J Appl Res Intellect Disabil 2015;28:414-22.

13 Day SM, Reynolds RJ, Kush SJ. Extrapolating published survival curves to obtain evidence-based estimates of life expectancy in cerebral palsy. Dev Med Child Neurol 2015;57:1105-18.

14 Oakeshott P, Hunt GM, Poulton A, et al. Expectation of life and unexpected death in open spina bifida: a 40 -year complete, non-selective, longitudinal cohort study. Dev Med Child Neurol 2010;52:749-53. 
15 World Health Organization. Global recommendations on physical activity for health. Geneva: WHO, 2010.

16 Carlon SL, Taylor NF, Dodd KJ, et al. Differences in habitual physical activity levels of young people with cerebral palsy and their typically developing Peers: a systematic review. Disabil Rehabil 2013;35:647-55

17 Lee I-M, Shiroma EJ, Lobelo F, et al. Effect of physical inactivity on major non-communicable diseases worldwide: an analysis of burden of disease and life expectancy. Lancet 2012;380:219-29.

18 Wen CP, Wai JPM, Tsai MK, et al. Minimum amount of physical activity for reduced mortality and extended life expectancy: a prospective cohort study. Lancet 2011;378:1244-53.

19 Cadilhac DA, Cumming TB, Sheppard L, et al. The economic benefits of reducing physical inactivity: an Australian example. Int J Behav Nutr Phys Act 2011;8:99.

20 Dodd KJ, Shields N. A systematic review of the outcomes of cardiovascular exercise programs for people with down syndrome. Arch Phys Med Rehabil 2005;86:2051-8.

21 Novak I, Mclntyre S, Morgan C, et al. A systematic review of interventions for children with cerebral palsy: state of the evidence. Dev Med Child Neurol 2013;55:885-910.

22 Oliveira A, Jácome C, Marques A. Physical fitness and exercise training on individuals with spina bifida: a systematic review. Res Dev Disabil 2014:35:1119-36.

23 George CL, Oriel KN, Blatt PJ, et al. Impact of a community-based exercise program on children and adolescents with disabilities. $J$ Allied Health 2011;40:55E-60.

24 Bremer E, Crozier M, Lloyd M. A systematic review of the behavioural outcomes following exercise interventions for children and youth with autism spectrum disorder. Autism 2016;20:899-915.

25 Bates L, Kearns R, Witten K, et al. 'A level playing field': young people's experiences of wheelchair basketball as an enabling place. Health Place 2019;60:102192.

26 Morris A, Imms C, Kerr C, et al. Sustained participation in community-based physical activity by adolescents with cerebral palsy: a qualitative study. Disabil Rehabil 2019;41:3043-51.

27 Shields N, Synnot AJ, Barr M. Perceived barriers and facilitators to physical activity for children with disability: a systematic review. $\mathrm{Br} \mathrm{J}$ Sports Med 2012;46:989-97.

28 Shields N, Synnot A. Perceived barriers and facilitators to participation in physical activity for children with disability: a qualitative study. BMC Pediatr 2015;16:1-10.

29 Mahy J, Shields N, Taylor NF, et al. Identifying facilitators and barriers to physical activity for adults with Down syndrome. J Intellect Disabil Res 2010;54:795-805.

30 Shields N, Taylor NF, Wee E, et al. A community-based strength training programme increases muscle strength and physical activity in young people with Down syndrome: a randomised controlled trial. Res Dev Disabil 2013;34:4385-94.

31 Shields N, Taylor NF. A student-led progressive resistance training program increases lower limb muscle strength in adolescents with Down syndrome: a randomised controlled trial. J Physiother 2010;56:187-93.

32 Shields N, Taylor NF. The feasibility of a physical activity program for young adults with down syndrome: a phase II randomised controlled trial. J Intellect Dev Disabil 2015;40:115-25.

33 Shields N, Bruder A, Taylor N, et al. Influencing physiotherapy student attitudes toward exercise for adolescents with Down syndrome. Disabil Rehabil 2011;33:360-6.

34 Shields N, Taylor NF. Contact with young adults with disability led to a positive change in attitudes toward disability among physiotherapy students. Physiother Can 2014;66:298-305.

35 Shields N, Taylor NF. Physiotherapy students' self-reported assessment of professional behaviours and skills while working with young people with disability. Disabil Rehabil 2014;36:1834-9.

36 Shields N, van den Bos R, Buhlert-Smith K, et al. A communitybased exercise program to increase participation in physical activities among youth with disability: a feasibility study. Disabil Rehabil 2019;41:1152-9.

37 Curran GM, Bauer M, Mittman B, et al. Effectiveness-implementation hybrid designs: combining elements of clinical effectiveness and implementation research to enhance public health impact. Med Care 2012;50:217-26.

38 Hemming K, Haines TP, Chilton PJ, et al. The stepped wedge cluster randomised trial: rationale, design, analysis, and reporting. BMJ 2015;350:h391.

39 McConkey R, Walsh J. An index of social competence for use in determining the service needs of mentally handicapped adults. $J$ Ment Defic Res 1982;26:47-61.
40 Norton K, Norton L. Pre-exercise screening: guide to the Australian adult pre-exercise screening system. Adelaide: Exercise and Sport Science Australia, 2011.

41 American College of Sports Medicine. ACSM's guidelines for exercise testing and prescription. Philadelphia, PA: Wolters Kluwer, 2017

42 Imms C, Granlund M, Wilson PH, et al. Participation, both a means and an end: a conceptual analysis of processes and outcomes in childhood disability. Dev Med Child Neurol 2017;59:16-25.

43 Willis C, Nyquist A, Jahnsen R, et al. Enabling physical activity participation for children and youth with disabilities following a goaldirected, family-centred intervention. Res Dev Disabil 2018;77:30-9.

44 Anaby DR, Law M, Feldman D, et al. The effectiveness of the pathways and resources for engagement and participation (PreP) intervention: improving participation of adolescents with physical disabilities. Dev Med Child Neurol 2018;60:513-9.

45 Kramer JM, Roemer K, Liljenquist K, et al. Formative evaluation of project team (teens making environment and activity modifications). Intellect Dev Disabil 2014;52:258-72.

46 McPherson AC, Rudzik A, Kingsnorth S, et al. "Ready to take on the world": experiences and understandings of independence after attending residential immersive life skills programs for youth with physical disabilities. Dev Neurorehabil 2018;21:73-82.

47 Peterson JJ, Lowe JB, Peterson NA, et al. Paths to leisure physical activity among adults with intellectual disabilities: self-efficacy and social support. Am J Health Promot 2008;23:35-42.

48 National Information Communication Awareness Network (NICAN). National Recreation guidelines. Canberra: Disability Services Queensland, 2004.

49 Bowen DJ, Kreuter M, Spring B, et al. How we design feasibility studies. Am J Prev Med 2009;36:452-7.

50 lacono T, Tracy J, Keating J, et al. The interaction with disabled persons scale: revisiting its internal consistency and factor structure, and examining item-level properties. Res Dev Disabil 2009;30:1490-501.

51 Nickless A, Voysey M, Geddes J, et al. Mixed effects approach to the analysis of the stepped wedge cluster randomised trial-Investigating the confounding effect of time through simulation. PLoS One 2018;13:e0208876.

52 White IR, Horton NJ, Carpenter J, et al. Strategy for intention to treat analysis in randomised trials with missing outcome data. BMJ 2011;342:d40.

53 Thorne S. Interpretive description: qualitative research for applied practice. London, UK: Routledge, 2016.

54 Tong A, Sainsbury P, Craig J. Consolidated criteria for reporting qualitative research (COREQ): a 32-item checklist for interviews and focus groups. Int J Qual Health Care 2007;19:349-57.

55 Liamputtong P. Qualitative research methods. Melbourne: Oxford University Press, 2013

56 Husereau D, Drummond M, Petrou S, et al. Consolidated health economic evaluation reporting standards (CHEERS)--explanation and elaboration: a report of the ISPOR health economic evaluation publication guidelines good reporting practices task force. Value Health 2013;16:231-50.

57 Feldstein AC, Glasgow RE, practical A. A practical, robust implementation and sustainability model (PriSM) for integrating research findings into practice. Jt Comm J Qual Patient Saf 2008;34:228-43.

58 United Nations. Convention on the rights of persons with disability. New York, NY: United Nations, 2006.

59 Booth ML, Okely AD, Chey TN, et al. The reliability and validity of the adolescent physical activity recall questionnaire. Med Sci Sports Exerc 2002;34:1986-95.

60 Hardy LL, Booth ML, Okely AD. The reliability of the adolescent sedentary activity questionnaire (ASAQ). Prev Med 2007;45:71-4.

61 King G, Law M, King S, et al. Children's assessment of participation and enjoyment and preferences for activities of children. San Antonio: Harcourt Assessment Inc, 2004.

62 Woodmansee C, Hahne A, Imms C, et al. Comparing participation in physical recreation activities between children with disability and children with typical development: a secondary analysis of matched data. Res Dev Disabil 2016;49-50:268-76.

63 Coster W, Law M, Bedell G, et al. Participation and environment measure for children and youth (PEM-CY). Boston, MA: Boston University, 2010

64 Coster W, Bedell G, Law M, et al. Psychometric evaluation of the participation and environment measure for children and youth. Dev Med Child Neurol 2011;53:1030-7.

65 King G, Batorowicz B, Rigby P, et al. Development of a measure to assess youth self-reported experiences of activity settings (seas). Int J Dis Dev Ed 2014;61:44-66. 
66 King G, Rigby P, Batorowicz B, et al. Development of a direct observation measure of environmental qualities of activity settings. Dev Med Child Neurol 2014;56:763-9.

67 King G, Rigby P, Avery L. Revised measure of environmental qualities of activity settings (MEQAS) for youth leisure and life skills activity settings. Disabil Rehabil 2016;38:1509-20.

68 Ratcliffe J, Couzner L, Flynn T, et al. Valuing child health utility 9D health states with a young adolescent sample: a feasibility study to compare best-worst scaling discrete-choice experiment, standard gamble and time trade-off methods. Appl Health Econ Health Policy 2011;9:15-27.

69 Stevens KJ. Working with children to develop dimensions for a preference-based, generic, pediatric, health-related quality-of-life measure. Qual Health Res 2010;20:340-51.

70 Stevens K. Assessing the performance of a new generic measure of health-related quality of life for children and refining it for use in health state valuation. Appl Health Econ Health Policy 2011;9:157-69.

71 Stevens K, Ratcliffe J. Measuring and valuing health benefits for economic evaluation in adolescence: an assessment of the practicality and validity of the child health utility 9D in the Australian adolescent population. Value Health 2012;15:1092-9.

72 Marks B, Heller T, Sisirak J. Exercise and nutrition health education curriculum for adults with developmental disabilities. Chicago, IL: Brookes, 2006.

73 Heller T, Hsieh K, Rimmer JH. Attitudinal and psychosocial outcomes of a fitness and health education program on adults with Down syndrome. Am J Ment Retard 2004;109:175-85.

74 O'Neil ME, Fragala-Pinkham M, Lennon N, et al. Reliability and validity of objective measures of physical activity in youth with cerebral palsy who are ambulatory. Phys Ther 2016;96:37-45.

75 McGarty AM, Penpraze V, Melville CA. Calibration and crossvalidation of the actiGraph wGT3X+ accelerometer for the estimation of physical activity intensity in children with intellectual disabilities. PLoS One 2016;11:e0164928.

76 Casey AF, Wang X, Osterling K. Test-retest reliability of the 6-minute walk test in individuals with Down syndrome. Arch Phys Med Rehabil 2012;93:2068-74.

77 Maher CA, Williams MT, Olds TS. The six-minute walk test for children with cerebral palsy. Int J Rehabil Res 2008;31:185-8. 